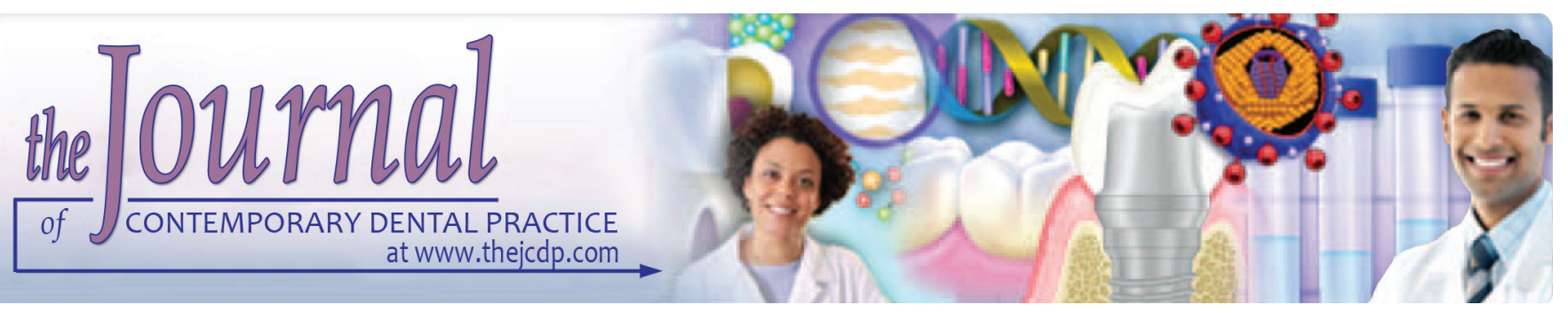

\title{
Evaluation of Proliferative Marker Ki-67 in Adenoid Cystic Carcinoma: A Retrospective Study
}

${ }^{1}$ Smita Bussari, ${ }^{2}$ Prabhakar A Jeergal, ${ }^{3}$ Manish Sarode, ${ }^{4}$ Nasim AK Namazi, ${ }^{5}$ Pavan G Kulkarni, ${ }^{6}$ Anjum Deshmukh, ${ }^{7}$ Dinraj Kulkarni

\begin{abstract}
Aim: Adenoid cystic carcinoma (ACC) is a malignant tumor of salivary gland origin. Although the histologic appearance of ACC is low grade, management of this malignancy is a distinct therapeutic challenge because of its tendency for perineural involvement and potential for distant metastasis. Ki-67 antigen is expressed during the $G_{1}, S, G_{2}$ and $M$ phases in the cell cycle but is absent in the quiescent $G_{0}$ phase in tissue sections. Aim of the study was to review hematoxylin and eosin stained slides in order to confirm the previous histopathological diagnosis as per the criteria given by World Health Organisation (WHO) and to evaluate the expression of cell proliferation marker, $\mathrm{Ki}-67$ antigen in Adenoid cystic carcinoma and correlate the expression of Ki-67 antigen histopathologically with different grades in Adenoid cystic carcinoma.
\end{abstract}

Materials and methods: Tissue samples of 32 cases (12 males and 20 females) were selected from minor salivary glands with age range from 21 to 70 years. Two paraffin-embedded sections of these total 32 cases each of $4 \mu \mathrm{m}$ thick were cut on a rotary microtome. One section was stained using hematoxylin and Eosin (H\&E) and the other was used for Immunohistochemical staining with $\mathrm{Ki}-67$ antigen.

\footnotetext{
1,4,6,7 Department of Oral Pathology and Microbiology, MA Rangoonwala College of Dental Science and Research Centre, Pune, Maharashtra, India

${ }^{2}$ Department of Oral Pathology and Microbiology, Sudha Rustagi College of Dental Science and Research, Faridabad, Haryana, India

${ }^{3}$ Department of Oral Pathology and Microbiology, Gurugobind Singh Dental College and Research Centre, Burhanpur, Madhya Pradesh, India

${ }^{5}$ Department of Oral Pathology and Microbiology, Kamineni Institute of Dental Sciences, Narketpally, Nalgonda, Telangana, India

Corresponding Author: Smita Bussari, Department of Oral Pathology and Microbiology, MA Rangoonwala College of Dental Science and Research Centre, Pune, Maharashtra, India, Phone: +919881107615, 9323999697, e-mail: drsmitabussari@ gmail.com
}

Results: Among these 32 cases of Adenoid cystic carcinoma, Histologically 14 (43.75\%) tumors were classified in grade I, 8 $(25 \%)$ were in grade II, and $10(31.25 \%)$ were in grade III. The average percentage of $\mathrm{Ki}-67$ expression was $27.12 \%$ in grade I, $34.43 \%$ in grade II and $38.45 \%$ in grade III.

Conclusion: Ki-67 immunoreactivity increased with increase in histopathological grades of ACC.

Clinical significance: Since Ki-67 is a useful marker for assessing the proliferative potential of tumors, the prognosis of patients can definitely be predicted.

Keywords: Adenoid cystic carcinoma, Ki-67, Immunohistochemistry.

How to cite this article: Bussari S, Jeergal PA, Sarode M, Namazi NAK, Kulkarni PG, Deshmukh A, Kulkarni D. Evaluation of Proliferative Marker Ki-67 in Adenoid Cystic Carcinoma: A Retrospective Study. J Contemp Dent Pract 2019;20(2):211-215.

Source of support: Nil

Conflict of interest: None

\section{INTRODUCTION}

Tumors of the salivary glands constitute an important area in the field of oral and maxillofacial pathology. Salivary gland tumors are reported to represent between $1 \%$ and $5 \%$ of all head and neck tumors and are either benign or malignant. ${ }^{1}$ Adenoid cystic carcinoma (ACC) compromises of $5-10 \%$ of malignant salivary gland tumors and is most commonly located in minor salivary glands (31\%). To palate is the most common site in minor salivary glands. ACC may occur at any age although most patients are middle-aged or older. ${ }^{2,3}$ The peak incidence is in the 5 th and 6 th decades. ${ }^{2}$ It is predominant in females when it occurs in submandibular gland but occurs equally in men and women when found in minor salivary glands. ${ }^{3}$ ACC was first described by Roth in 1856. Histopathologically Seifert has described three growth patterns Solid, tubular and cribriform. ${ }^{3,4}$ Immunohistochemistry is an effective adjuvant to histopathological diagnosis based on $\mathrm{H}$ and E stained sections in the majority of equivocal tumor 
cases through the establishment of definitive diagnosis or confirmation of $\mathrm{H}$ and $\mathrm{E}$ stained sections. It can be used to predict the prognosis of patients by evaluating cell proliferation with the help of proliferation markers such a PCNA, Ki-67, and JCI, etc. 5,6

MIB1, a monoclonal antibody that points at Ki-67 antigen in formalin fixed paraffin embedded tissues was used to determine the proliferative activity of tumors. ${ }^{6}$

The purpose of the study was to assess the validity of $\mathrm{Ki}-67$, a cell proliferation marker, as a prognostic factor by evaluating the expression of Ki-67 antigen in ACC and to correlate histopathologically with different grades in ACC.

\section{MATERIALS AND METHODS}

\section{Tissue Sample}

This retrospective study was performed on formalin fixed, paraffin embedded tissue specimens from 32 patients with Adenoid Cystic Carcinoma diagnosed over the period of 1969-2008 from the archive of oral pathology Department of Government dental college Nagpur. This study included 12 males and 20 females with an age range from 21 to 70 years. The tissue samples considered were paraffin embedded tissue blocks. Two paraffinembedded sections of 32 cases each of $4 \mu \mathrm{m}$ thick were cut on a rotary microtome and one section was stained with Haematoxylin and Eosin ( $\mathrm{H}$ and $\mathrm{E})$ stain and other section was used for immunohistochemical staining with monoclonal antibody anti-ki-67 antigen. All the $\mathrm{H}$ and $\mathrm{E}$ stained sections were classified as per WHO International Classification of Salivary gland tumors in 2005 . $^{7}$

\section{Immunohistochemical Staining Procedure}

Sections of $4 \mu \mathrm{m}$ thickness were cut from formalin-fixed and paraffin-embedded tissue blocks and mounted on silane-coated glass slides. Paraffin sections were deparaffinized in xylene. Sections were rehydrated by transferring through descending grades of alcohol to water. Slides were heated in a pressure cooker for a total of 10 minutes in sodium citrate buffer $(0.01 \mathrm{M}, \mathrm{pH}$ 6.0) for antigen retrieval. Sections were incubated with peroxide block ( $3 \%$ hydrogen peroxide in water) and washed with PBS (pH 7.4, 0.05 M) 3 times for 5 minutes each. The sections were incubated with power block (contains casein and proprietary additives in PBS with $0.09 \%$ sodium azide) for 10 minutes at room temperature to block nonspecific immune reactions. Section was covered with Ready-touse mouse monoclonal antibody (Anti-Ki-67 antigen, Biogenics) and incubated in a humidifying chamber at room temperature $\left(\approx 25^{\circ} \mathrm{C}\right)$ for 60 minutes and then kept overnight at $4^{\circ} \mathrm{C}$. Appropriate volume $(\approx 38 \mu \mathrm{L})$ of super enhancer reagent was added to cover the specimen according to tissue size to amplify the antigen-antibody reaction. The appropriate volume of Poly-HRP reagent was added to cover the specimen and incubated for $30 \mathrm{~min}$ at room temperature $\left(\approx 25^{\circ} \mathrm{C}\right)$ and rinsed thoroughly with PBS (pH 7.4, $0.05 \mathrm{M}$ ) thrice. Substrate solution (DAB) was added to cover the specimen and incubated for $30 \mathrm{~min}$ at room temperature $\left(\approx 25^{\circ} \mathrm{C}\right)$ and rinsed with $\mathrm{PBS}(\mathrm{pH} 7.4$, $0.05 \mathrm{M})$ at least thrice. The sections were counterstained with Mayer's hematoxylin and mounted with a coverslip using Disterene Polystyrene xylene (DPX).

\section{Assessment of Immunohistochemically Stained Sections}

Immunohistochemically stained sections were assessed on the light microscope under X400 magnification and evaluated for Ki-67 positive cells. Cells were considered positive for the Ki-67 antigen if there was intranuclear DAB staining (brown color). All stained nuclei were scored positive regardless of the intensity of staining. Cells that lacked the clear nucleus were excluded. The counting protocol suggested by Hirabayashi ${ }^{8}$ and Okabe et al. ${ }^{9}$ was followed. Five fields showing maximum Ki-67 positive cells were selected at X100 magnification, and a minimum of 1000 tumor cells was counted in each section at X400 magnification. Computer-assisted cell counting was done using a cell Image Analyzer (Olympus BX51). The number of positively stained nuclei was expressed as a percentage of the total number of tumor cells counted per section which is known as Ki-67 Labeling Index (Ki-67 LI).

Ki-67 Labeling Index $=\frac{(\text { Number of Ki-67 positive nuclei) } X 100}{(\text { Ki-67 LI) (total number of tumor cells observed })}$

\section{Statistical Analysis}

Analysis of the correlation between Ki-67 LI and different grades of Adenoid cystic carcinoma was performed using unpaired t-test and Kruskal-Wallis test. $P$ values were noted using software INTERCOOLED STATA version 8.

$p$ values of $<0.05$ were regarded as significant.

\section{RESULTS}

All 32 cases of adenoid cystic carcinoma with respect to age, sex, location, and grade of the tumor over the period of 1969 to 2008 are shown in Table 1. Patients included 12 $(37.5 \%)$ males and 20 (62.5\%) females, male:female ratio was 1:1.66. The average age in this study was 46 years (range 21-70 yrs) in males and 44 years in females. All tumors were from minor salivary glands, 15 (46.87\%) were located in the palate, 9 (28.12\%) in buccal mucosa, $5(15.62 \%)$ in the retromolar region and $3(9.37 \%)$ on labial mucosa. as shown in Table 2.

Total 32 cases of Adenoid cystic carcinoma were stained according to hematoxylin and eosin method to 
confirm the diagnosis and then classified according to the International Classification of Salivary Gland Tumors. They were classified into grade I (Fig. 1A), grade II (Fig. 2A) and grade III (Fig. 3A). The ki-67 evaluation was done in all the grades of ACC grade I (Fig. 1B), grade II (Fig. 2B) and grade III (Fig. 3B). Among these 32 cases of ACC, histologically 14 (43.75\%) tumors were classified in grade I, 8 (25\%) were in grade II and 10 (31.25\%) were in grade III. The average percentage of Ki-67 expression was $27.12 \%$ in grade I, $34.43 \%$ in grade II and $38.45 \%$ in Grade III as shown in Table 3. The difference in ki-67 expression in grades I and III was statistically significant $(p<0.05)$, whereas the difference in Grade II and Grade III was not statistically significant $(p>0.05)$.

\section{DISCUSSION}

Adenoid cystic carcinoma is a rare tumor accounting for 2 to $4 \%$ of all head and neck tumours. ${ }^{2}$ It most commonly occurs in minor salivary glands and palate is the most common site in our study, $46.87 \%$ occurred in the palate. In a study by Rapidis et al. ${ }^{2}$ male to female ratio is $1: 1.6$, which showed female predominance. ${ }^{4}$ In our study male:female ratio was 1:1.66 with a female predominance. The mean age of patients was 46 yrs in males and 44 yrs in females in our study this was in accordance with studies by Rapidis et al., ${ }^{2}$ Szanto et al., ${ }^{3}$ Seifert et al., ${ }^{7}$ and Gneep. ${ }^{10}$

Microscopically tumor showed duct lining cells and cells of myoepithelial type. Szanto et al. ${ }^{3}$ described three

Table 1: Demographic distribution of adenoid cystic carcinoma over the period of 1969-2008

\begin{tabular}{|c|c|c|c|c|c|}
\hline Sr. No. & Grade of $A C C$ & Age (years) & Sex & Location & Year of diagnosis \\
\hline 1. & 1 & 38 & $M$ & Palate & 1969 \\
\hline 2. & III & 40 & $\mathrm{~F}$ & Buccal mucosa & 1971 \\
\hline 3. & I & 30 & $M$ & Palate & 1975 \\
\hline 4. & II & 47 & $\mathrm{~F}$ & Retromolar area & 1978 \\
\hline 5. & III & 57 & $\mathrm{~F}$ & Palate & 1982 \\
\hline 6. & III & 25 & M & Retromolar area & 1982 \\
\hline 7. & 1 & 42 & $\mathrm{~F}$ & Buccal mucosa & 1982 \\
\hline 8. & I & 60 & $M$ & Palate & 1982 \\
\hline 9. & III & 40 & $\mathrm{~F}$ & Labial mucosa & 1985 \\
\hline 10. & I & 48 & $\mathrm{~F}$ & Buccal mucosa & 1987 \\
\hline 11. & I & 21 & M & Palate & 1987 \\
\hline 12. & 1 & 54 & M & Retromolar area & 1987 \\
\hline 13. & III & 40 & $\mathrm{~F}$ & Palate & 1989 \\
\hline 14. & III & 22 & $\mathrm{~F}$ & Buccal mucosa & 1991 \\
\hline 15. & 1 & 64 & M & Palate & 1992 \\
\hline 16. & ॥ & 55 & $\mathrm{~F}$ & Labial mucosa & 1993 \\
\hline 17. & I & 45 & $\mathrm{~F}$ & Palate & 1993 \\
\hline 18. & III & 35 & $\mathrm{~F}$ & Labial mucosa & 1993 \\
\hline 19. & I & 34 & $M$ & Palate & 1995 \\
\hline 20. & ॥ & 49 & $\mathrm{~F}$ & Buccal mucosa & 1995 \\
\hline 21. & I & 43 & $\mathrm{~F}$ & Palate & 1995 \\
\hline 22. & III & 38 & $M$ & Retromolar area & 1997 \\
\hline 23. & I & 52 & $\mathrm{~F}$ & Buccal mucosa & 1999 \\
\hline 24. & I & 47 & $\mathrm{~F}$ & Palate & 2000 \\
\hline 25. & III & 67 & $M$ & Palate & 2000 \\
\hline 26. & I & 39 & $\mathrm{~F}$ & Retromolar area & 2003 \\
\hline 27. & $\|$ & 59 & $M$ & Buccal mucosa & 2003 \\
\hline 28. & ॥ & 35 & $\mathrm{~F}$ & Palate & 2005 \\
\hline 29. & II & 27 & $\mathrm{~F}$ & Buccal mucosa & 2007 \\
\hline 30. & III & 70 & $\mathrm{~F}$ & Palate & 2007 \\
\hline 31. & II & 62 & $M$ & Buccal mucosa & 2007 \\
\hline 32. & $\|$ & 47 & $\mathrm{~F}$ & Palate & 2008 \\
\hline
\end{tabular}

Table 2: Distribution of tumor location in patients with ACC $(\mathrm{n}=32)$

\begin{tabular}{llll}
\hline Sr. no & Location & Frequency & Percentage $(\%)$ \\
\hline 1. & Palate & 15 & 46.87 \\
2. & Buccal mucosa & 9 & 28.12 \\
3. & Retromolar area & 5 & 15.62 \\
4. & Labial mucosa & 3 & 9.37 \\
\hline
\end{tabular}



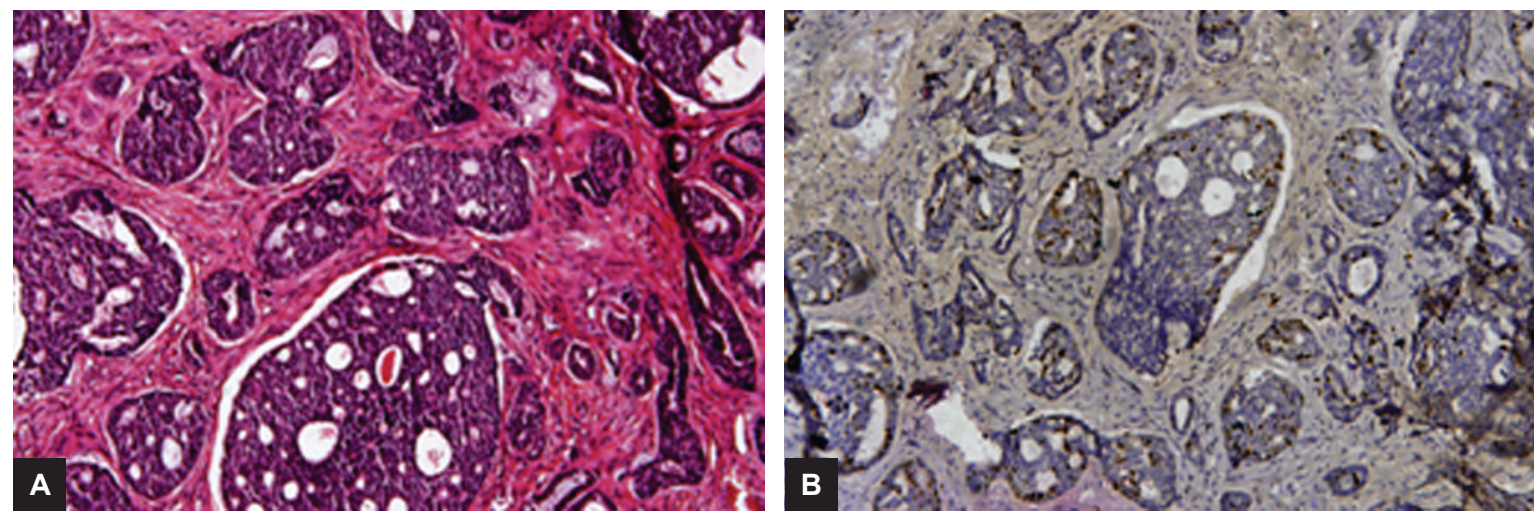

Figs 1A and B: (A) Adenoid cystic carcinoma grade I ( $\mathrm{H}$ and E stain, 10x magnification); (B) Adenoid cystic carcinoma grade I (Immunohistochemical stain, Ki-67 positive nuclei, 10x magnification)
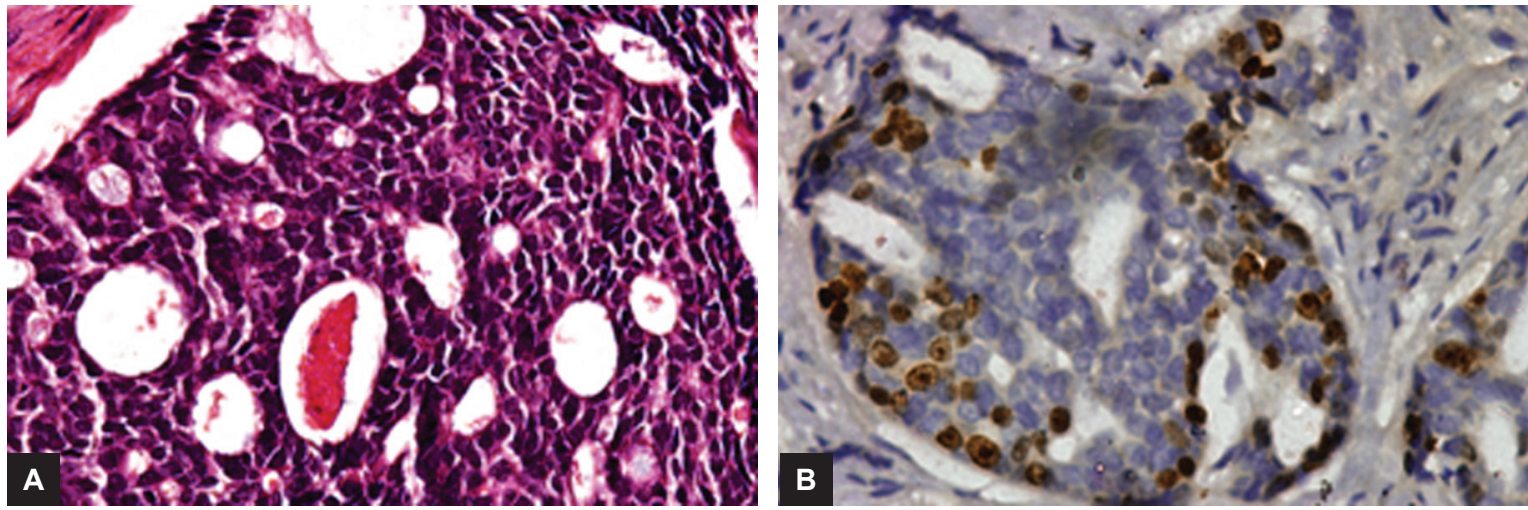

Figs 2A and B: (A) Adenoid cystic carcinoma grade II ( $\mathrm{H}$ and E stain, 40x magnification); (B) Adenoid cystic carcinoma grade II (Immunohistochemical stain, Ki-67 positive nuclei, 40x magnification)
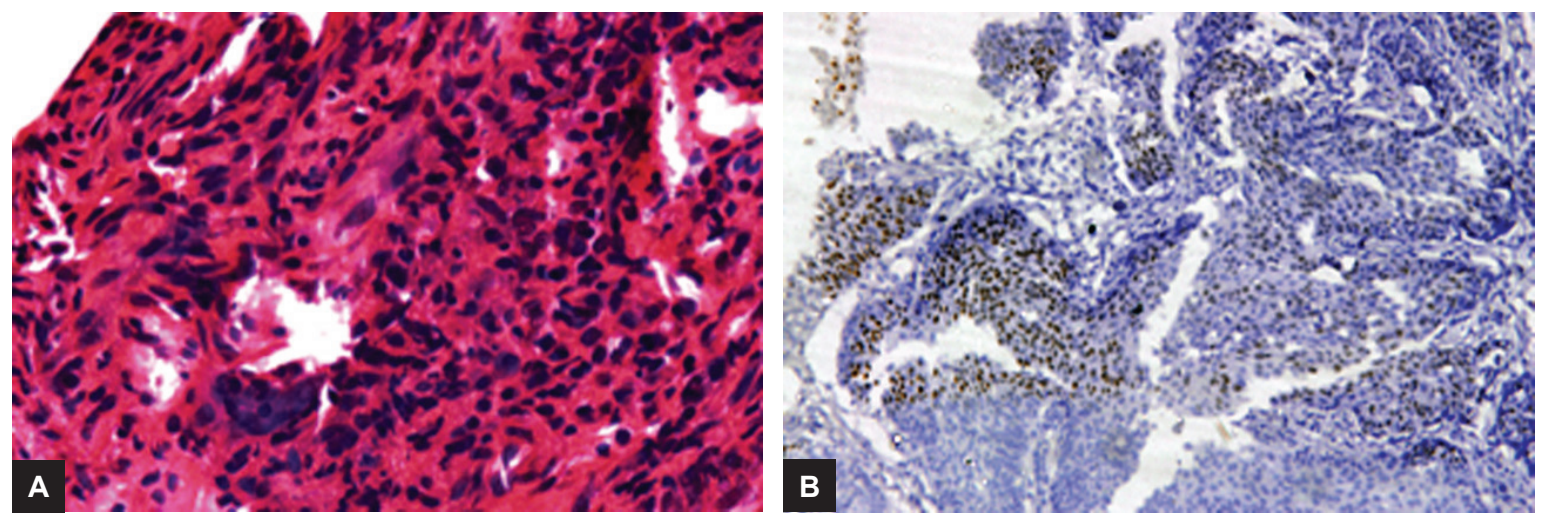

Figs 3A and B: (A) Adenoid cystic carcinoma grade III (H and E stain, 40x magnification); (B) Adenoid cystic carcinoma Grade II (Immunohistochemical stain, Ki-67 positive nuclei, 40x magnification)

Table 3: Correlation between grade of the tumor and Ki-67 expression

\begin{tabular}{llllll}
\hline Grade & frequency & Average of Ki-67 & Standard deviation & Standard error & Range of expression \\
\hline I & 14 & 27.12 & 24.23 & 6.25 & $0-60$ \\
II & 8 & 34.43 & 22.97 & 13.43 & $0-55$ \\
III & 10 & 38.45 & 4.85 & 14.5 & $25-80$ \\
\hline
\end{tabular}

histological grades for ACC. Grade I tumors with tubular and cribriform areas but without solid component, grade II cribriform tumors that are pure or mixed with $30 \%$ of solid areas. Grade III tumors with a predominantly solid pattern. The histologically tubular pattern was most common. $43.75 \%$ of the tumors in this study were Grade I, $25 \%$ in grade II and $31.25 \%$ in grade III.
The monoclonal antibody Ki-67 was first described in 1983 by Johannes Gerdes and colleagues, who suggested that it might be used as a marker for proliferating cells. The word $\mathrm{Ki}$ is derived from the name of University called Kiel, where Johannes Gerdes in the lab of Harald Stein generated the antibody. It was the 67 th well of a 96 wee microtitre plate, so it was designated Ki-67. The Ki-67 
protein, detected by immunolocalization of the Ki-67 antigen is located in the nucleus, and its gene is located on the chromosome 10 q25-ter. ${ }^{5}$

The Ki-67 is a human nuclear antigen that is expressed during the $G_{1}, S, G_{2}$ and $M$ phases in the cell cycle, but it is absent in the quiescent $G_{0}$ phase. In tissue sections, the Ki-67 antigen is used to localize the Ki-67 protein (pKi-67). The antibody raised against the Ki-67 antigen has been used as a simple, rapid and reliable means of evaluating the growth fraction of normal and neoplastic cell population. $\mathrm{Ki}-67$ protein is used as a growth fraction marker. It detects the proportion of cells committed to the cell cycle hence it assess the state of cell proliferation., 5 In this study we observed that average Ki-67 immunoreactivity was 27.12 in grade I, 34.43 in grade II and 38.45 in grade III, The mean percentage of $\mathrm{Ki}-67$ expression increased with increase in grade of the tumor. Hirabayashi. ${ }^{8}$ reported that Ki-67 LI of the solid pattern is greater than that of the cribriform pattern. Nordgard reported that the average percentage of Ki-67 expression increased with histological grade of tumor in ACC.

This study was in correlation with Hirabayashi and Nordgard. ${ }^{8,11} \mathrm{Ki}-67$ expression ratio greater than $10 \%$ indicated a more aggressive tumor in the study by Norberg et al. ${ }^{12}$ Similar finding was observed with Triantafillidou et al. ${ }^{13}$ and Giannoi et al. ${ }^{14}$ in contrast Carlinfante et al. ${ }^{15}$ found no correlation of marker to histological type, clinical staging, and survival.

\section{CONCLUSION}

This study evaluated the immunohistochemical expression of Ki-67 antigen in ACC arising from salivary glands and showed a significant correlation between Ki-67 expression and grade of the tumor. However, a further large number of studies are needed to confirm this issue.

\section{REFERENCES}

1. Ellis Gl, Auclair PL, Gnepp DR. Surgical pathology of salivary glands. Philapdelphia: WB Saunders Company; 1991:108-164.
2. Rapidis AD, Givalos N, Gakiopoulou H, Faratzis G, Stavrianos $\mathrm{SD}$, Vilos GA et al. Adenoid cystic carcinoma of head and neck. Clinicopathological analysis of 23 patients and review of the literature. Oral Oncolog. 2005:41:328-335.

3. Szanto PA, Luna MA, Tortoledo ME, White RA. Histologic grading of adenoid cystic carcinoma of the salivary glands. Cancer 1984;54:1062-1069.

4. Van der Waal JE, Becking AG, Snow GB, Van der Waal I; 2002, Distant metastasis of adenoid cystic carcinoma of the salivary glands and the value of diagnostic examinations during follow-up Head Neck 779-783.

5. Brown DC, Gatter KC. Monoclonal antibody Ki-67: its use in histopathology Histopathology 1990;17:489-503.

6. Hall PA, Levison DA. Review: Assessment of cell proliferation in histological material. J Clin Pathol 1990;43:184-192.

7. Seifert G, Sobin LH. Histological classification of salivary gland tumours, in WHO International Histological Classification of Tumours. (ed 3) Lyon, 2005.

8. Hirabayashi S. Immunohistochemical detection of DNA topoisomerase type II $\alpha$ and $\mathrm{Ki}-67$ in adenoid cystic carcinoma and pleomorphic adenoma of the salivary gland. J Oral Pathol Med 1999;28:131-136.

9. Okabe $\mathrm{M}$, Inagaki $\mathrm{H}$, Murase $\mathrm{T}$, Inoue $\mathrm{M}$, Nagai $\mathrm{N}$, Eimoto $\mathrm{T}$. Prognostic significance of p27 and Ki-67 expression in mucoepidermoid carcinoma of the intraoral minor salivary gland. Mod Pathol 2001;14(10):1008-1014.

10. Gneep DR. Diagnostic surgical pathology of the head and neck. Philadelphia: WBSaunders. 2001;379.

11. Nordgard S, Franzen G, Boysen M, Halvorsen TB. Ki-67 as a prognostic marker in adenoid cystic carcinoma assessed with the monoclonal antibody MIB-1 in paraffin sections. Laryngoscope 1997;107:5:31-36.

12. Norberg-Spaak L, Dardick I, Ledin T Adenoid cystic carcinoma use of cell proliferation, Bcl-2 expression histological grade and clinical stage as predictors of clinical outcome. Head Neck 2000;22:489-497.

13. Triantafillidou K, Dimitrakopoulos J, Iordanidis F, Koufogiannis. Management of Adenoid cystic carcinoma of minor salivary glands. J. Oral Maxillofac Surg 2006;64:1114-1120.

14. Giannoni C, El-Naggar AK, Ordonez NG, Tu Zn, Austin J, Luna MA, Batakis JG. C-erb-2/neu oncogene and of palatal salivary gland neoplasms. Otolaryngol Head Neck Surg.1995;112:391-398.

15. Carlinfante G, Lazzaretti M, Ferrari S, Bianchi b, Crafa B, P53 bcl-2 and Ki-67 expression in adenoid cystic carcinoma of palate. A clinicopathological study of 21 cases with long term follow up. Pathol. Res Pract 2005;200:791-799. 